\title{
Повседневные практические задачи требуют инновационных аналитических решений
}

\section{В. В. Родченкова}

\begin{abstract}
Учебно-научная химико-аналитическая лаборатория РГУ нефти и газа (НИУ) имени И. М. Губкина - одна из ведущих в Российской Федерации испытательных лабораторий в заявленной области аккредитации. Больше двадцати лет под руководством академика РАН А. Г. Дедова ученые-химики успешно решают самые сложные практические задачи по созданию методов контроля состояния окружающей среды, водных ресурсов, лекарственных препаратов, качества нефтепродуктов и др. Важное и очень востребованное направление работы - разработка экспресс-методов и многокомпонентных тест-средств для контроля качества топлив и смазочных материалов. Об истории создания лаборатории, достижениях, практических результатах работы и планах на будущее рассказали руководитель - ак. Алексей Георгиевич Дедов и заместитель руководителя лаборатории, менеджер по качеству Делгир Андреевна Санджиева.
\end{abstract}

\section{ИСТОРИЯ, ЦЕЛИ И ПРИЧИНЫ СОЗДАНИЯ ЛАБОРАТОРИИ}

В 1996 году на кафедре общей и неорганической химии Российского государственного университета нефти и газа (национальный исследовательский университет) имени И.М.Губкина была создана Учебно-научная химикоаналитическая лаборатория. С момента основания руководит лабораторией Алексей Георгиевич Дедов - заведующий кафедрой, академик РАН, профессор, доктор химических наук.

Деятельность лаборатории с самого начала была направлена на решение самых важных народно-хозяйственных задач.

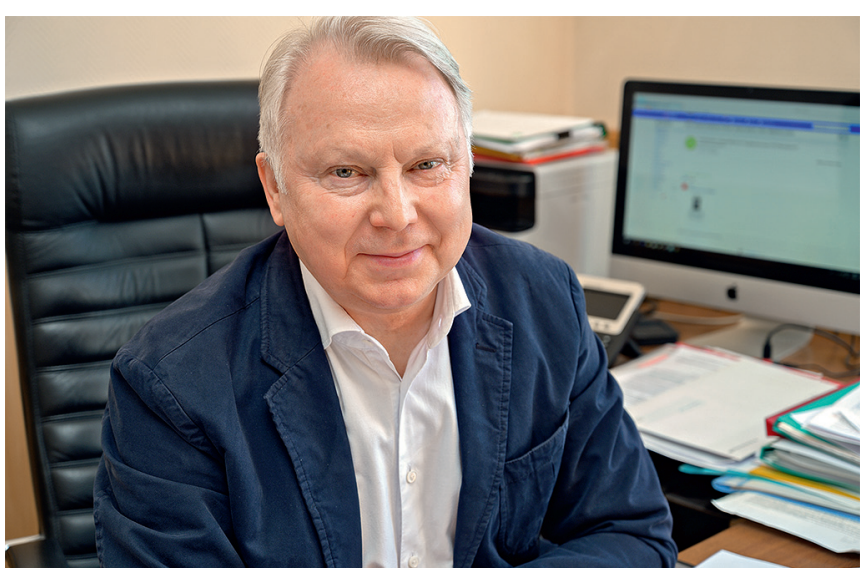

Алексей Георгиевич Дедов
Например, в начале 1990-х годов была актуальна проблема обнаружения и идентификации озоноразрушающих веществ (ОРВ) в продукции, ввозимой на территорию России. В связи с принятием Монреальского протокола (Правительство РФ подписало его в 1987 году, а также изменения 1992 года) возникла необходимость наладить контроль озоноразрушающих веществ в продукции при трансграничных перевозках. Постановлением Правительства РФ от 6 ноября 1992 года № 854, Приложение № 1, был утвержден Перечень озоноразрушающих веществ, ввоз и вывоз которых подлежал госрегулированию. Государственный комитет по охране окружающей среды поручил ак. А. Г.Дедову возглавить группу по разработке методики обнаружения хлорфторуглеводородов, часто называемых фреонами или хладонами. Фреоны используются в кондиционерах, холодильном оборудовании, осушителях воздуха, льдогенераторах, переносных огнетушителях, аэрозольной продукции, вспенивателях и т.д. Специально для системы контроля под руководством ак. А. Г.Дедова была разработана методика определения присутствия озоноразрушающих веществ в образцах газообразных проб методом ИК-спектроскопии. Вспениватели и порообразователи исследовали методом хромато-массспектрометрии, для чего специалистами лаборатории были подобраны условия пробоподготовки.

Еще одна задача, которая была решена в лаборатории в те годы, позволила таможенной службе определять содержание спиртов. Так в области аккредитации появилось качественное и количественное определение этанола в продукции различного назначения. Методика на основе 


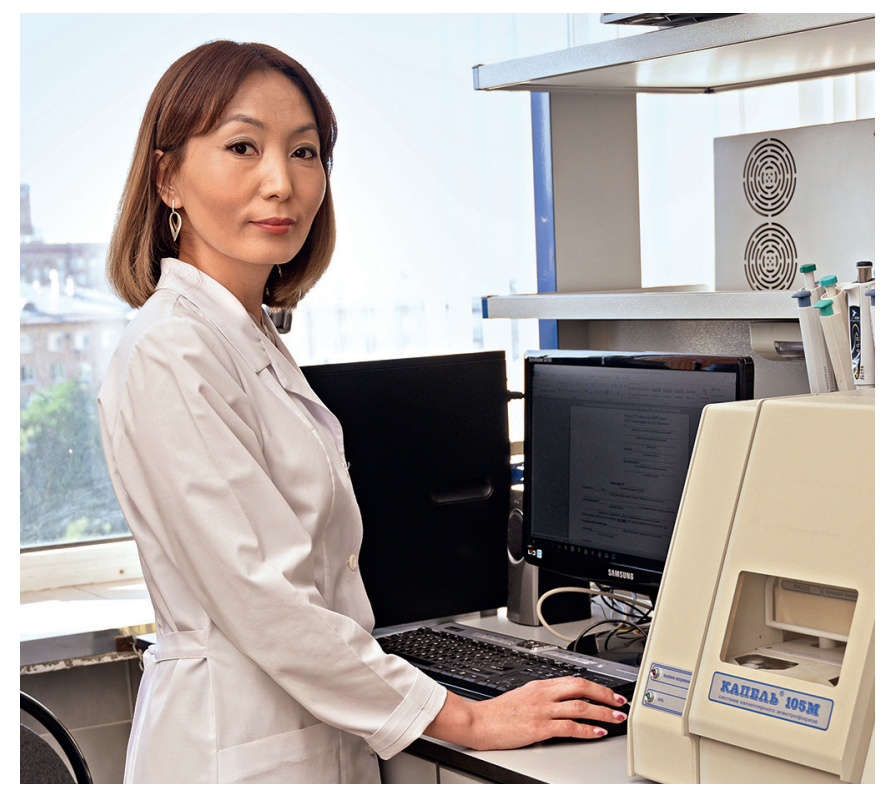

Делгир Андреевна Санджиева

хромато-масс-спектрометрии также была разработана под руководством ак. А. Г.Дедова.

Постепенно лаборатория и сфера ее деятельности расширялись, в область аккредитации вошла проверка воды сточной, технологической, природной, питьевой, в том числе расфасованной в емкости.

В конце 1990-х годов сильно возросло число автомобилей на улицах столицы, что стало причиной резкого ухудшения состояния окружающей среды. По распоряжению мэра Москвы впервые был введен норматив Евро 2 (1996 год), согласно которому ограничивалось содержание серы в топливах и поэтому потребовалось организовать контроль их качества. Сначала Департамент транспорта, а затем Департамент природопользования и охраны окружающей среды правительства Москвы заключили договоры с несколькими лабораториями, в том числе и с лабораторией РГУ нефти и газа (НИУ) имени И. М. Губкина. Кэтому времени (1998 год) область аккредитации лаборатории уже включала испытание нефти и нефтепродуктов на соответствие ГОСТ, а сейчас - и Техническому регламенту Таможенного союза.

Сегодня Учебно-научная химико-аналитическая лаборатория РГУ нефти и газа (НИУ) имени И. М. Губкина - одна из ведущих в Российской Федерации испытательных лабораторий в заявленной области аккредитации.

В апреле 2019 года Ассоциацией аналитических центров "Аналитика" Учебно-научная химико-аналитическая лаборатория РГУ нефти и газа (НИУ) имени И. М. Губкина признана лучшей и удостоена награды “Серебряный моль».

\section{сотрудники}

Лаборатория создана на базе главного университета страны по подготовке специалистов для нефтегазовой отрасли. Работающие в лаборатории специалисты имеют серьезную теоретическую и практическую подготовку. Это позволяет качественно выполнять работу, соответствующую профилю выполняемых испытаний и оказывать грамотную консультативную помощь заказчикам.

В настоящее время коллектив лаборатории - это 13 сотрудников, в том числе два доктора химических наук (А. Г. Дедов, А. С. Локтев), пять кандидатов химических наук (Е.А. Иванова, Е. А. Исаева, О. В. Кузнецова, Д. Ю. Марченко, Д. А. Санджиева), а также инженеры А. А. Бурова, Е. В.Головачева, Т. Г. Исаева, И. Е.Мухин, А.П.Поляков, Г.М.Семикина.

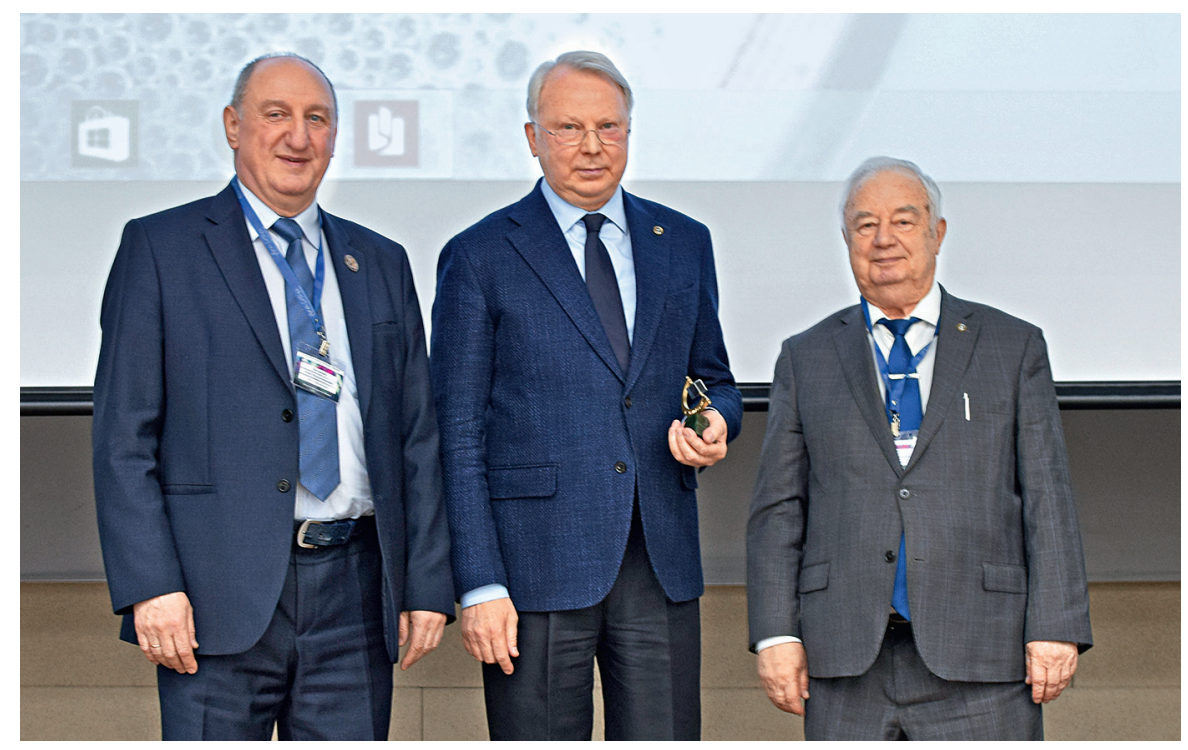

Вручение премии "Серебряный моль». Исполнительный директор ААЦ "Аналитика» И. В. Болдырев, ак. РАН А. Г. Дедов и президент ААЦ "Аналитика» ак. РАН Ю. А. Карпов

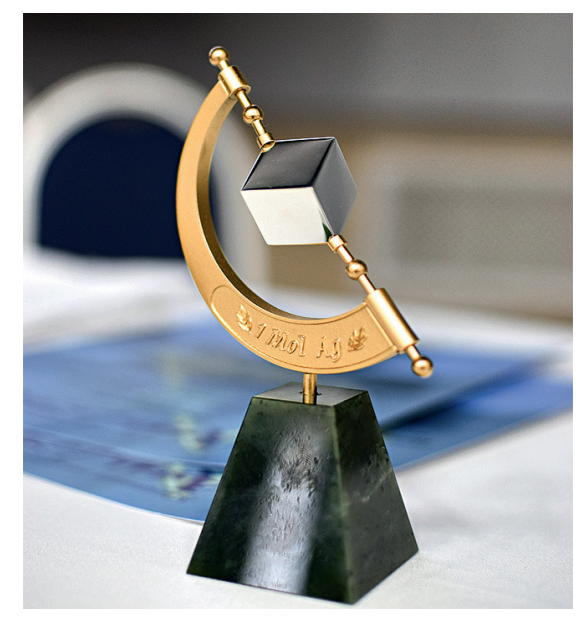

"Серебряный моль» - кубик из чистого серебра 999 пробы массой 107,87 2 (4то соответствует одному молю серебра), закрепленный на подставке, выполненной в форме микрометра 


\section{ЗАКАЗЧИКИ}

Лаборатория сотрудничает с ПАО «Газпром", ООО «ЛУКОЙЛЦентрнефтепродукт», правительством Москвы, ГУВД Москвы и др.

Кроме испытаний продукции, сотрудники лаборатории проводят научно-техническую экспертизу по поручению как государственных органов: судов, Генеральной прокуратуры, МВД, СК России, так и независимых компаний и частных лиц. Например, требуется не только проверить нефтепродукты на соответствие нормативной документации, но и идентифицировать их именно с целью подтверждения кодировки товара по номенклатуре внешнеэкономической деятельности.

\section{НАПРАВЛЕНИЯ РАБОТЫ, ОБЪЕКТЫ ИССЛЕДОВАНИЯ, МЕТОДЫ АНАЛИЗА И ОБОРУДОВАНИЕ}

В области аккредитации лаборатории более 150 методик анализа и испытаний. Специалисты проводят работы по следующим направлениям:

- испытания продукции (нефть, бензин, дизельное топливо, мазут и другие нефтепродукты, смазки и моторные масла, технические жидкости, газы углеводородные сжиженные автомобильные и топливные) на соответствие нормативным документам (техническим регламентам ЕАЭС, гОст и др.);

- определение содержания метилового, этилового и изопропилового спиртов в материалах и промышленной продукции различного назначения;

- идентификация и определение присутствия озоноразрушающих веществ, ввоз в РФ и вывоз из РФ которых подлежит государственному регулированию;

- количественный химический анализ воды питьевой, в том числе расфасованной в емкости, природной, сточной, технологической для тепловых электростанций.

Для такой сложной и разносторонней работы лаборатория снабжена современным аналитическим и испытательным оборудованием. При выполнении количественного и качественного химического анализа используются методы: атомно-абсорбционный; ИК-фурье-спектрометрия; капиллярный электрофорез; рентгеноспектральный флуоресцентный; потенциометрия; спектрофотометрия; хроматомасс-спектрометрический; хроматографический (газовая, высокоэффективная жидкостная); гравиметрический; различные виды титриметрии.

Каждый объект испытаний имеет свою специфику, которую необходимо учитывать при выполнении испытания и интерпретации его результатов. В частности, анализ нефтепродуктов характеризуется рядом особенностей, главная из которых многокомпонентность.

Нефтепродукт - понятие товарное, а не химическое, это не просто сложная смесь индивидуальных веществ. Например, всем известно, что автомобильный бензин - это продукт компаундирования. То есть товарный продукт - автомобильный бензин - на выходе с нефтеперерабатывающего завода (НП3) получают смешением бензиновых фракций 5-9 процессов. Нефтепродукты не имеют эталонной матрицы, следовательно, невозможно составить "базовую коллекцию” объектов исследования. И именно поэтому в стандартах зафиксирован не только перечень показателей качества моторных топлив, но и методы их испытаний, а целый ряд показателей качества бензинов носят условный характер (октановое число, окислительная стабильность и др.). Требование строго следовать методике со статусом государственного (национального) стандарта является гарантией точности и основой для сравнения результатов.

Дополнительной сложностью при испытаниях топлив и моторных масел является наличие в них различных присадок. Часть присадок нормируется, как, например, металлсодержащие добавки, и требует контроля. Такие испытания можно проводить только высокотехнологичными методами. Атомно-абсорбционный спектрометр нужен для обнаружения металлсодержащих присадок в бензинах, хромато-массспектрометр - для идентификации спиртов в охлаждающих и тормозных жидкостях.

Еще один интересный прибор - анализатор Cetane ID-510 для определения цетанового числа, которое является характеристикой воспламеняемости дизельного топлива. Традиционно цетановое число топлив определяется на одноцилиндровых установках типа Идт, которые требуют специальных помещений, сервисных подводок, стандартного топлива в больших количествах, постоянного обслуживания и замены расходных материалов и запасных частей. В лаборатории университета цетановое число определяется немоторным методом по стандарту ASTM D7668 на анализаторе Cetane ID-510. В основе метода испытания лежит математическая модель, связывающая цетановое число со временем задержки воспламенения. Режим работы прибора полностью автоматизирован, при этом повторяемость и воспроизводимость результатов, полученных на анализаторе Cetane ID-510, лучше, чем на установках ИДТ.

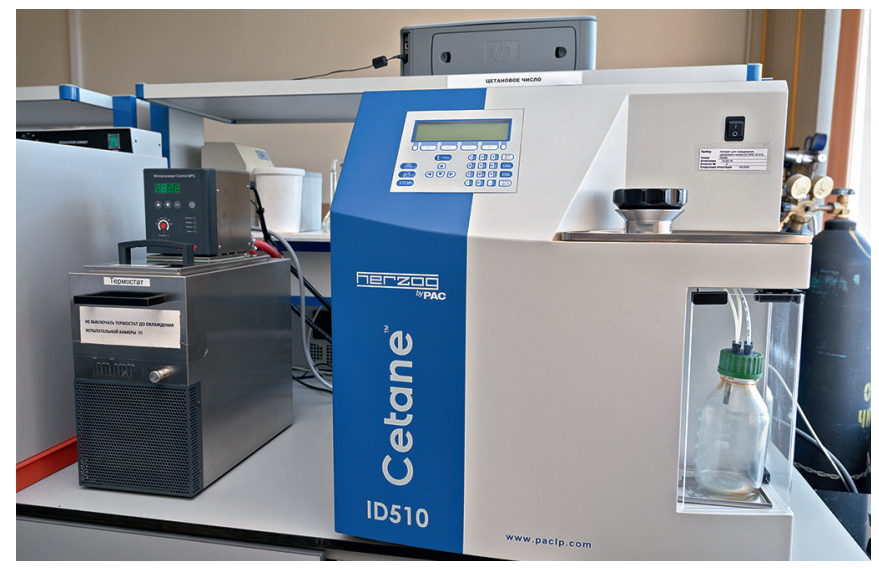

Анализатор цетанового числа дизельных топлив Cetane ID-510 


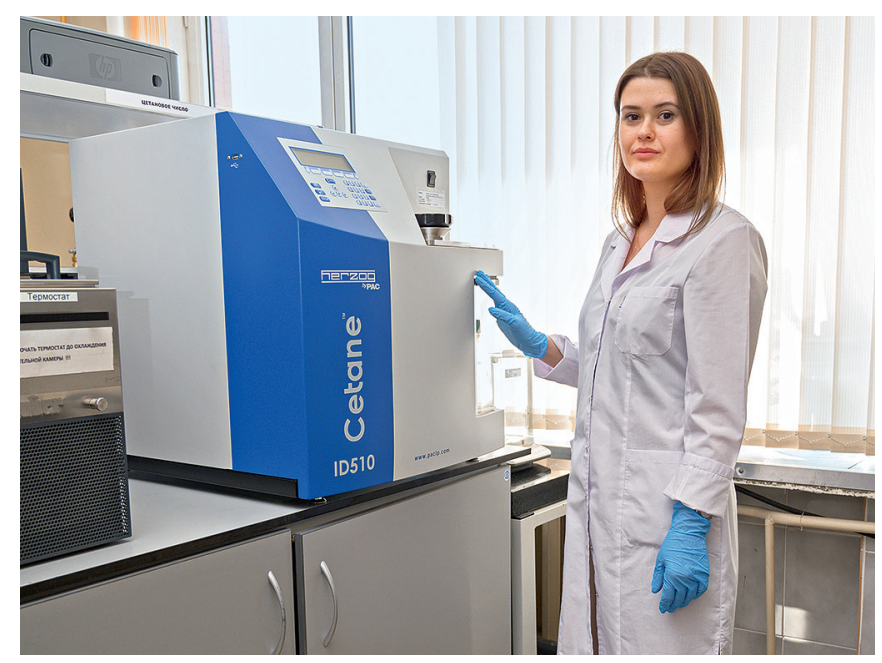

Aнастасия Бурова

В арсенале лаборатории имеется современное хроматографическое оборудование. Хроматографы используются для определения индивидуального и группового углеводородного состава топлив, в частности, объемной доли бензола, ароматических и олефиновых углеводородов, N-метиланилина, органических кислородсодержащих соединений и общего содержания органически связанного кислорода. Содержание полициклических ароматических углеводородов в дизельных топливах определяют методом ВЭЖХ.

Любое дизельное топливо, проходящее через систему впрыска, одновременно играет роль смазывающего материала. смазывающая способность - свойство жидкости сводить к минимуму трение между поверхностями и их повреждение при относительном движении этих поверхностей под нагрузкой. Чрезмерный износ приводит к выходу из строя топливного насоса, корпуса форсунок, повышению образования нагара, увеличению выброса отработанных газов, аварийной поломке двигателя, что часто объясняется недостаточными смазывающими способностями топлива.

Действующий в России Технический регламент Таможенного союза ТР ТС 013/2011 на топливо экологического класса 5 ограничивает содержание серы до "не более 10 мг/кг". Снижение содержания серы и ее соединений, которые играют роль природной присадки, приводит к уменьшению смазывающей способности топлива. Разумеется, производители топлив вводят противоизносные присадки для повышения смазывающей способности. Однако важность этого эксплуатационного показателя диктует необходимость его контроля.
Смазывающая способность топлива в соответствии с международным стандартом измеряется пятном износа на металлическом шарике, которое образуется в результате трения шарика о неподвижную металлическую пластину, полностью погруженную в топливо.

В лаборатории для определения смазывающей способности топлив используется аппарат системы HFRR (высокочастотное устройство возвратно-поступательного движения) фирмы PETROTECH в комплекте с электронным микроскопом 100-кратного увеличения (для измерения пятна износа), снабженным цифровым микрометром, имеющим разрешение 1 мкм. Результаты испытания смазывающей способности топлив на аппарате HFRR коррелируют с множеством комбинаций «топливо - деталь системы впрыска" и обеспечивают надежный прогноз уровня смазывающих свойств топлива.

Важной областью деятельности лаборатории являются научные исследования, посвященные разработке экспрессметодов контроля качества топлив. Вот что об этом рассказывает А. Г. Дедов: “В начале 1990-х нехватку высокооктанового бензина компенсировали добавлением металлсодержащих присадок. В связи с запретом тетраэтилсвинца (ТЭС) временно были допущены присадки на основе ферроцена. И вообще на рынке было много суррогатного топлива. Продавцы приспособились к проверкам: торговали плохим топливом в выходные дни, даже начиная в пятницу после обеда. Особенно летом, что объяснялось массовым выездом за город. Департамент транспорта организовал месячник по ежедневному контролю, в том числе и в выходные дни отбирал пробы. Результаты оказались просто вопиющими! Каждая вторая проба даже у крупных компаний не соответствовала требованиям постановления правительства Москвы. Надо отметить, что многие продавцы считали неправомерным на территории отдельного субъекта федерации устанавливать требования по экологическим показателям жестче, чем по ГОСТ. Но тогда Москва совсем бы задохнулась от выхлопных газов с высоким содержанием оксидов

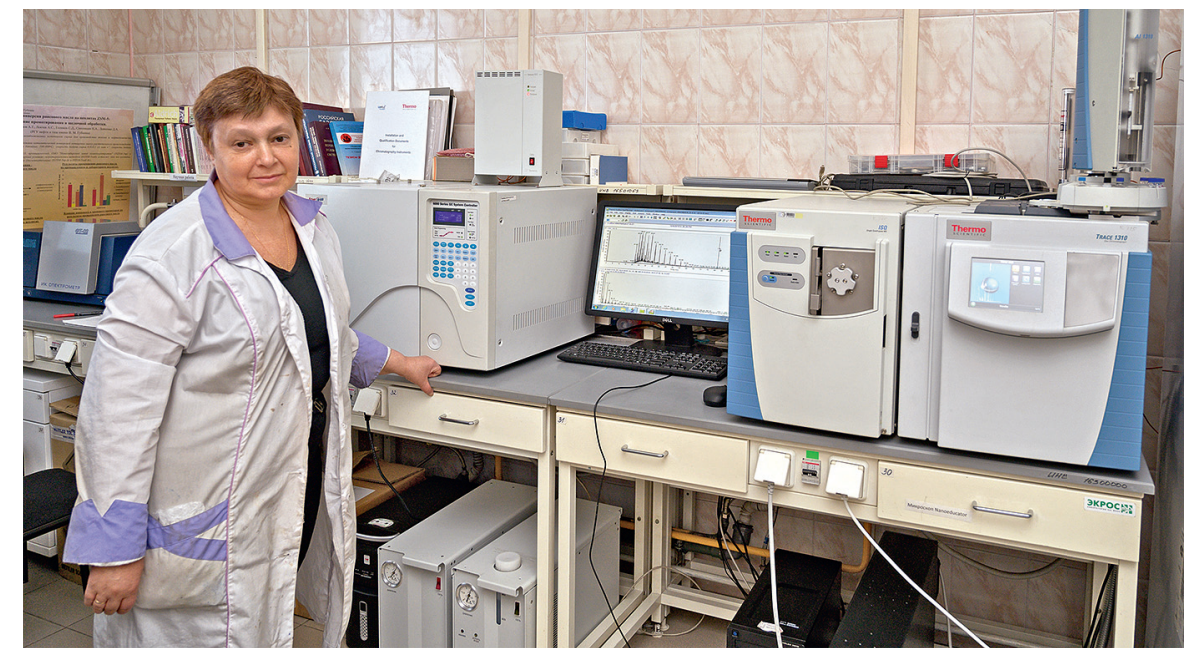

Екатерина Александровна Иванова, прибор ГХ-МС Trace 1310 (Termo Scientific) 


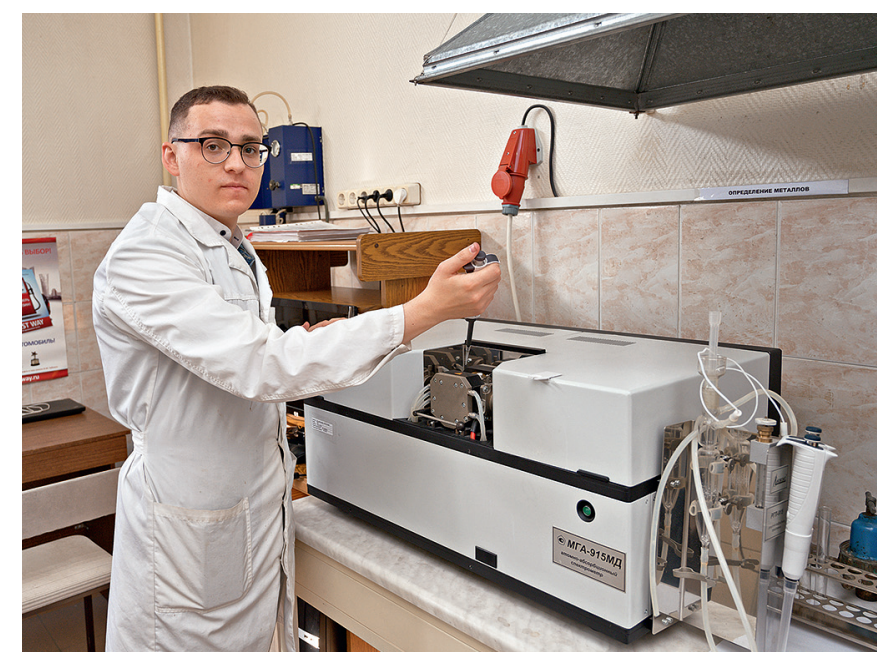

Александр Удовиченко определяет концентрацию металлов на атомно-абсорбционном спектрометре

серы! Поэтому было много случаев оспаривания штрафов в суде и много арбитражных проб привозили к нам в лабораторию. В итоге постепенно по всей стране на топливо был введен стандарт Евро. Кстати, сторонникам тезиса "рынок все исправит» пришлось согласиться, что только систематический контроль качества ставит заслон "плохой" продукции. В этой связи актуальной стала задача разработки экспресс-методов анализа".

На одной из встреч при посещении Губкинского университета Ю. М. Лужков, в то время мэр Москвы, высказал пожелание разработать тест-средства, чтобы выявлять некондиционное топливо еще до заправки, то есть вооружить потребителя простым и удобным экспресс-методом, чтобы он "голосовал рублем» на заправках! Так появились тест-полоски проверки бензина на наличие металлсодержащих присадок. Патент за разработку получила группа под руководством ак. А. Г. Дедова.

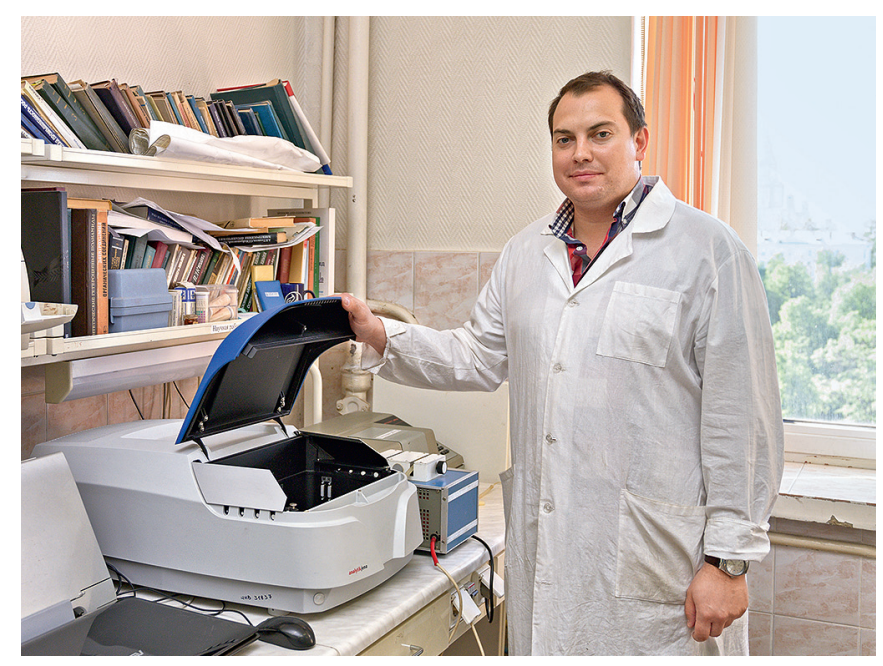

Игорь Евгеньевич Мухин

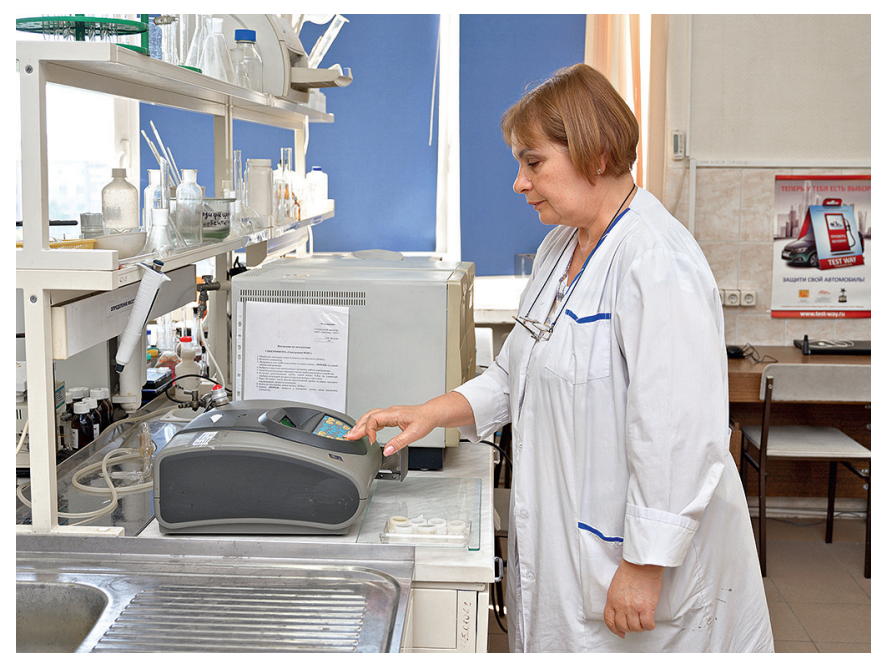

Ольга Викторовна Кузнецова определяет содержание серы в нефтепродуктах

В течение нескольких последних лет проводится разработка инновационных экспресс-тестов согласно требованиям ТР ТС 013/2011 к содержанию серы и монометиланилина в топливах экологического класса 5. Разрабатываемые экспресс-тесты представляют собой индикаторные таблетки, порошки, полоски и трубки на основе твердофазных реагентов, меняющие свой цвет под действием испытываемого топлива. Концентрацию контролируемых примесей в топливах или субстанции в лекарственном препарате определяют по интенсивности окраски тест-средства либо сравнивая с окрашенной шкалой, либо "цифровым способом" - с использованием офисного сканера или портативного полиграфического спектрофотометра.

Кроме того, недавно для одновременного определения серосодержащих и ароматических азотсодержащих соединений в составе жидких топлив сотрудниками лаборатории был предложен метод на основе тонкослойной хроматографии. Разработка этого подхода является существенным шагом к многокомпонентному экспресс-контролю топлив.

Конечно, экспресс-методы очень удобны, но ни в коем случае не заменяют испытания в аккредитованной лаборатории. Они полезны для потребителя и оценочного контроля.

\section{ПЛАНЫ НА БУДУЩЕЕ}

Жизнь ставит новые задачи. В частности, снижение нормативного содержания хлорорганических соединений в нефти до значений "не более 6 ррт" требует освоения новых методик. Продолжится разработка средств для многокомпонентного экспресс-контроля топлив, а также лекарственных препаратов. Кроме того, в последнее время актуальна проблема коррозии, вызванная биозагрязнением. Все эти задачи по плечу дружному коллективу квалифицированных специалистов.

Желаем всем сотрудникам успехов и новых научных открытий и свершений! 
СОБСТВЕННОЕ ПРОИЗВОДСТВО

ПРИБОРОВ -

ТЕХНОЛОГИЧЕСКИЙ СУВЕРЕНИТЕТ

Сколково

СТРАНЫ!

ФБУ «РОСТЕСТ-Москва»

CFPD_A 1 Предельная температура

ГOCT 22254 - EN 16329 - ГOCT P 54269

EN 116 - ASTM D6371 - IP 309

DIST-41 1 Фракционный состав

ГOCT 2177 - ГOCT P 53707 - ГOCT ISO 3405

ГОСТ Р ЕН ИСО 3405 - ASTM D 86 (гp. 0 - 4)

PMA-A1 1 Температура вспышки

ГОСТ Р ЕН ИСО 2719 - ГОСТ ISO 2719

ГOCT 6356 - ГOCT P 54279 - ASTM D93

TITRANTOO $\begin{aligned} & \text { Автоматический } \\ & \text { титратор }\end{aligned}$

ГOCT 17323 - ASTM D 3227 - ГOCT 28084

ГOCT 11362 - ГОСТ 25794.1 - ГОСТ 11362

\section{HFRR-MONO}

ASTM D 6079 - ГОСТ ИСО 12156

ГОСТ Р ИСО 12156
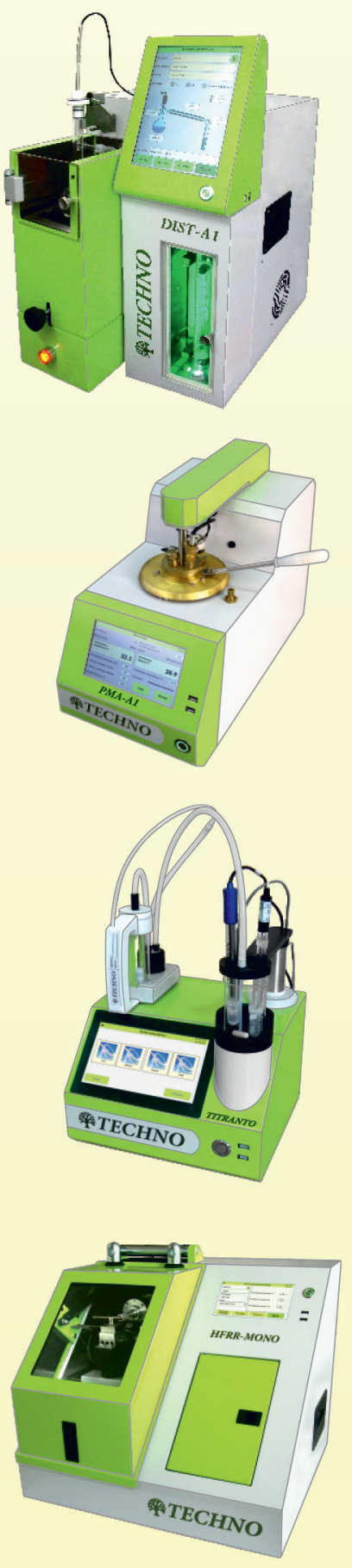